\title{
Concept and progress in coupling of dehydrogenation and hydrogenation reactions through catalysts
}

\author{
C V PRAMOD, C RAGHAVENDRA, K HARI PRASAD REDDY, G V RAMESH BABU, \\ K S RAMA RAO and B DAVID RAJU* \\ Inorganic and Physical Chemistry Division, Indian Institute of Chemical Technology, \\ Hyderabad 500 607, India \\ e-mail: david@iict.res.in
}

MS received 6 October 2013; revised 6 December 2013; accepted 12 December 2013

\begin{abstract}
This review focuses on the importance of coupling of catalytic reactions which involves dehydrogenation and hydrogenation simultaneously and the study of catalytic materials that are designed, adopted and/or modified for these reactions. The special features of these reactions are minimization of $\mathrm{H}_{2}$ utilization and reduction in production cost. Structural and textural properties also play a decisive role in this kind of coupled reactions. This particular review although not comprehensive discusses the significant progress made in the area of coupled reactions and also helps future researchers or engineers to find out the improvements required in areas such as advancements in catalytic material preparation, design of the new reactors and the application of new technologies.
\end{abstract}

Keywords. Coupling; hydrogenation; dehydrogenation; catalyst.

\section{Introduction}

Catalysis is an important field in chemistry where most of the chemical processes employ catalysts at least in one of their steps. ${ }^{1}$ Similarly, most biochemically significant processes are catalysed. A survey in the US showed that more than $60 \%$ of the 63 major products and $90 \%$ of the 34 process innovations from 1930 to 1980 have involved catalysis, which illustrates the vital role of this field in the fuel and chemical industries. $^{2}$ Catalytic reactions are preferred in environment-friendly green chemistry due to the reduced amount of waste generated; ${ }^{3}$ as opposed to stochiometric reactions in which all reactants are consumed and more side products are formed. In the beginning, only pure components were used as catalysts, but after 1900, multicomponent catalysts were studied and these are now commonly used catalysts in the industry today. ${ }^{4,5}$ Continuous research and development $(\mathrm{R} \& \mathrm{D})$ programmes are in progress in order to find new catalyst formulations to fulfill economic and environmental demands for various industrial reactions. In recent years, environmentally benign catalysts have gained more significance. Substantial importance has been given to developing a good active catalyst with a

\footnotetext{
*For correspondence
}

special emphasize on eco-friendly catalytic materials. In addition to this, economical use of a catalyst/catalyst material is important. Consequently, people are trying to reduce production cost in all possible ways. This can be vital for the chemical industry. In addition to this, importance of hydrogen is one more point to be considered while performing a hydrogenation reaction. Hence, all these constraints led the researchers to combine two individual reactions namely dehydrogenation and hydrogenation in which the former reaction acts as a hydrogen source. This combination can reduce the capital, time and hydrogen usage. As a result, $\mathrm{R} \& \mathrm{D}$ is concentrating on developing different catalyst systems which can serve as both hydrogenation and dehydrogenation catalysts.

Recently, a review has highlighted the coupling of exothermic and endothermic reaction, types of reactors that are used and various types of couplings. ${ }^{6}$

Research on coupling of reactions, mainly endothermic and exothermic has emerged as work of high significance. Coupling of two contradictory chemical transformations over a single catalyst bed has several advantages such as operational simplicity, mitigation of thermodynamic limitations, ${ }^{7}$ eco-friendly operations and enhanced product selectivity. As shown in scheme 1, reaction I involves dehydrogenation which is generally an endothermic equilibrium process and 


\section{$\mathrm{A} \stackrel{\text { Catalyst }}{\longrightarrow} \mathrm{C}+\mathrm{H}_{2} \longrightarrow \mathrm{I}$ \\ $\mathrm{B}+\mathrm{H}_{2} \stackrel{\text { Catalyst }}{\longrightarrow} \mathrm{D}$

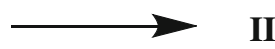 \\ $\mathbf{A}+\mathbf{B} \stackrel{\text { Catalyst }}{\longrightarrow} \mathbf{C}+\mathbf{D}$ \\ III}

Scheme 1. General scheme of individual and coupling reactions.

is governed by Le chatelier's principle and reaction II is a hydrogenation reaction which in most cases is an exothermic process. When the reactions I and II are performed simultaneously, the hydrogen released in reaction I will be used up in reaction II, enhancing conversions in reaction I (by Le chatelier's principle). Hence, this process provides an advantage of avoiding the usage of external $\mathrm{H}_{2}$. An additional benefit of this coupling process is maintainance of good thermal balance, and hydrogen in adsorbed form produced during dehydrogenation process is more reactive compared than molecular hydrogen in gaseous phase. Thus, the study of coupling processes have gained importance in recent times. It is necessary to study the coupling reactions intrinsic factors, screen the catalysts and optimize the operating conditions before such a process is carried out. Hence, various research groups started working on the coupling processes and obtained encouraging results.

\section{Scope of the review}

The major purpose of this survey is to excavate literature on coupling of dehydrogenation-hydrogenation reactions. It presents us the present status of coupled reactions in the area of catalysis. It reveals various catalytic materials used for various combinations of reactions and their operating conditions. It also presents the disadvantages, improvements/modifications to be made and suggestions to improve the yields and gaps to be filled to take these reactions to commercial scale.

\subsection{Advantage in usage of $\mathrm{CO}_{2}$}

Several researchers coupled the dehydrogenation reaction with $\mathrm{CO}_{2}$ flow. In 1988, Sato et al. conducted dehydrogenation of ethyl benzene $(\mathrm{EB})$ to styrene in presence of $\mathrm{CO}_{2}$ over sodium oxide $/ \mathrm{Al}_{2} \mathrm{O}_{3}$ catalyst. ${ }^{8}$ Thereafter, more studies on development of this reaction were reported which could achieve gradual improvement in the reaction output. ${ }^{9-17}$ Some of them revealed that the presence of $\mathrm{CO}_{2}$ oxidizes the oxygen defects of the metal oxides present in the catalyst. Various other reports that dealt with the nature of acidic/basic sites and other parameters were published using modified and unmodified $\mathrm{ZrO}_{2}, \mathrm{TiO}_{2}, \mathrm{MnO}_{2}$ and $\mathrm{CeO}_{2}$ materials. ${ }^{18-22}$ All the reports emphasized the benefit of using $\mathrm{CO} / \mathrm{CO}_{2}$ as co-feed. The advantages of this coupling are that $\mathrm{CO}_{2}$ could suppress the catalyst deactivation; formation of syn gas (mixture of carbon monoxide and hydrogen) and utilization of global warming culprit, $\mathrm{CO}_{2}$. However, the second process which is a reverse water-gas shift reaction (RWGS) is also an endothermic reaction which requires high temperatures. Mimura et al. ${ }^{12}$ used steam in the dehydrogenation process to supply heat, to dilute EB for increasing conversion and to avoid coke deposition on the catalyst. It was reported that equilibrium conversion of $\mathrm{EB}$ to styrene is greater in presence of $\mathrm{CO}_{2}$ than in presence of steam. Also, though the RWGS is endothermic in nature, shifting of equilibrium from EB to styrene is more dominant in steam.

Integrated membrane reactors were used to synthesize styrene and cyclohexane simultaneously. ${ }^{23,24}$ Wang et al. have reported the coupling of $\mathrm{EB}$ in presence of nitrobenzene using supported Pt catalysts. ${ }^{25}$ Studies on coupling of EB and nitrobenzene (NB) with focus on EB dehydrogenation at low temperatures were reported. ${ }^{26-28}$ Zhu et al. (2002) reported the coupling of hydrogenation of maleic anhydride (MA) and dehydrogenation of 1,4-butanediol (BDO) over $\mathrm{Cu}-\mathrm{Zn}$ catalysts. ${ }^{29}$ They have reported that by coupling two reactions, reaction temperatures decreased by $30-50^{\circ} \mathrm{C}$, which is because of the rich active hydrogen species generated on the catalyst surface. Further, Yang et al.

Table 1. Physico-chemical characteristics of the catalysts.

\begin{tabular}{lccccc}
\hline & & & \multicolumn{3}{c}{$\mathrm{N}_{2} \mathrm{O}$ pulse chemisorption results } \\
\cline { 3 - 5 } S1. No & Catalyst & BET surface area $\left(\mathrm{m}^{2} / \mathrm{g}\right)$ & $\mathrm{Cu}$ dispersion $(\%)$ & $\mathrm{MSA}\left(\mathrm{m}^{2} / \mathrm{g}\right) \times 10^{19}$ & Cu crystallite size $(\mathrm{nm})$ \\
\hline 1 & $\mathrm{CM}$ & 25 & 12.1 & 11.57 & 45 \\
2 & $\mathrm{CA}$ & 68 & 13.4 & 14.53 & 30 \\
3 & $\mathrm{CS}$ & 150 & 20.6 & 23.2 & 20 \\
4 & $\mathrm{CHT}$ & 60 & 10.3 & 13.3 & 33 \\
\hline
\end{tabular}


Table 2. $\mathrm{NH}_{3} \mathrm{TPD}$ results of the catalysts.

\begin{tabular}{|c|c|c|c|c|}
\hline Sl. No & Catalyst & Temperature $(\mathrm{K})$ & Acidic strength & Volume of $\mathrm{NH}_{3}$ desorbed $(\mu \mathrm{ml} / \mathrm{g})$ \\
\hline \multirow[t]{3}{*}{1} & \multirow[t]{3}{*}{$\mathrm{CM}$} & 336 & Weak & 15 \\
\hline & & 592 & Moderate & 33 \\
\hline & & 970 & Strong & 74 \\
\hline \multirow[t]{2}{*}{2} & \multirow[t]{2}{*}{$\mathrm{CA}$} & 359 & Very weak & 223 \\
\hline & & 494 & Moderate & 893 \\
\hline \multirow[t]{3}{*}{3} & \multirow[t]{3}{*}{$\mathrm{CS}$} & 346 & Very weak & 108 \\
\hline & & 522 & Moderate & 65 \\
\hline & & 933 & Strong & 30 \\
\hline 4 & $\mathrm{CHT}$ & 643 & Moderate & 97 \\
\hline
\end{tabular}

modified the $\mathrm{Cu}-\mathrm{Zn}$ catalysts with $\mathrm{Al}$, and used it in the synthesis of butyrolactone (BL) and 2-methylfuran (MF) by the coupling of 1,4-butanediol and furfural. ${ }^{30}$

Research has continued on various catalytic materials for a number of coupled reactions by our group producing different varieties of industrially important compounds. Initially, $\mathrm{Cu}-\mathrm{MgO}$ catalysts were used to produce furfuryl alcohol and cyclohexanone $(\mathrm{CHN})$ by the coupling of cyclohexanol (CHA) dehydrogenation and furfural (FA) hydrogenation. ${ }^{31}$ Producing encouraging results. Later, $\mathrm{Cu}-\mathrm{MgO}-\mathrm{Cr}_{2} \mathrm{O}_{3}$ catalysts were employed in the same reaction. ${ }^{32}$ It is observed that the addition of $\mathrm{Cr}_{2} \mathrm{O}_{3}$ as a promoter enhanced the activity and decreased the particle size of $\mathrm{Cu}$ when compared to that of unpromoted catalyst. A US patent has been granted for the same study. ${ }^{33}$ Another coupling reaction of 1,4-butanediol and nitrobenzene was

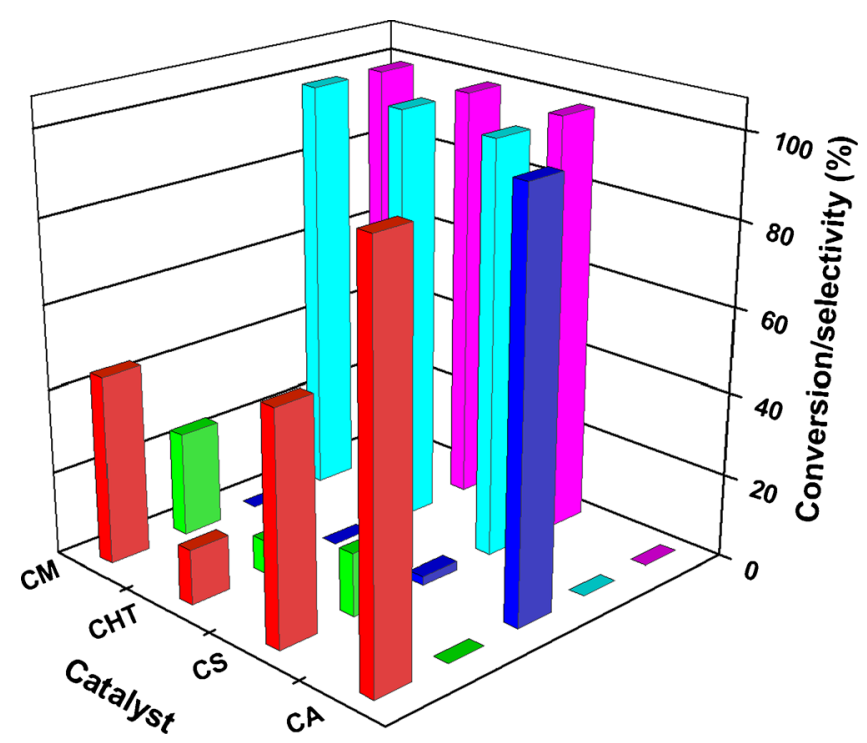

Figure 1. Activity profile of various $\mathrm{Cu}$ catalysts. Reaction conditions: 1 atm, temperature $=523 \mathrm{~K}, 0.5 \mathrm{~g}$ catalyst, 1 , $4 \mathrm{BDO} / \mathrm{NB}=3 / 2, \mathrm{~N}_{2}$ flow $=18 \mathrm{ml} / \mathrm{min}$. Conversion of 1, 4 BDO. Conversion of NB. Selectivity to THF. Selectivity to GBL. Selectivity to ANL. reported over $\mathrm{Cu}-\mathrm{MgO}$ catalyst. $^{34}$ The same catalyst system was also tried in the coupling of acetophenone and 1,4-butanediol. ${ }^{35}$ Effect of metal loading and the method of preparation involving $\mathrm{Cu}-\mathrm{MgO}-\mathrm{Al}_{2} \mathrm{O}_{3}$ (precursor such as hydrotalcite) catalyst were studied in the coupling of cyclohexanol and nitrobenzene. ${ }^{36,37}$ Preparation method of the catalyst also plays a vital role in metal dispersion. ${ }^{38}$ The synergy mechanism was wellestablished between the reactant molecules in all those reported coupled reactions. Moreover, the conversions increased significantly in the coupled reactions when compared to that of individual reactions which serves as an additional advantage of these coupled reactions.

In addition to the above mentioned coupled reactions, continuous research on new catalysts suitable for various coupled reactions was carried out. Keeping $10 \mathrm{wt} \%$ of $\mathrm{Cu}$ (active metal) in each catalyst, various supports such as $\mathrm{MgO}, \mathrm{Al}_{2} \mathrm{O}_{3}, \mathrm{SiO}_{2}$, and $\mathrm{Mg}$ Al HT have been chosen keeping the strength of acidities in mind for the coupling of 1,4-butanediol (1,4-BDO) dehydrogenation and NB hydrogenation reaction. Physico-chemical characteristics of catalysts (CM, CA, CS and CHT represents $\mathrm{Cu} / \mathrm{MgO}$, $\mathrm{Cu} / \mathrm{Al}_{2} \mathrm{O}_{3}, \mathrm{Cu} / \mathrm{SiO}_{2}$ and $\mathrm{Cu} / \mathrm{HT}$ catalysts, respectively) are displayed in table 1 . Table 2 shows the acidic strengths of the catalysts at different temperatures. Experimental procedure for catalyst characterization was followed according to procedure given in literature. ${ }^{39}$ It is observed that the BET surface areas of catalysts are on the lower side when compared to bare supports $\left(\mathrm{MgO}=42 \mathrm{~m}^{2} / \mathrm{g}, \mathrm{Al}_{2} \mathrm{O}_{3}=180 \mathrm{~m}^{2} / \mathrm{g}\right.$, $\mathrm{HT}=80 \mathrm{~m}^{2} / \mathrm{g}, \mathrm{SiO}_{2}=380 \mathrm{~m}^{2} / \mathrm{g}$ ). From the $\mathrm{N}_{2} \mathrm{O}$ pulse chemisorption studies, it is evident that the support influences surface $\mathrm{Cu}$ species and active metal area and thereby metal particles. Figure 1 shows the activity profile of the coupling of 1,4-butanediol dehydrogenation and nitrobenzene hydrogenation at 523 K. Figure 1 and table 2 show that although metal dispersion is higher for CS catalyst, the material with non-acidic sites/moderate basic sites play an 
Table 3. Physical characteristics of the catalysts.

\begin{tabular}{lcccccc}
\hline \multirow{2}{*}{ Sl. No } & Catalyst & $\begin{array}{c}\text { BET surface } \\
\text { area }\left(\mathrm{m}^{2} / \mathrm{g}\right)\end{array}$ & \multicolumn{2}{c}{ XRD phases } & $\begin{array}{c}\text { Crystallite size of } \\
\text { reduced catalysts }(\mathrm{nm})\end{array}$ & $\begin{array}{c}\text { Crystallite size of } \\
\text { spent catalysts (nm) }\end{array}$ \\
\hline 1 & $5 \mathrm{CM}$ & 30 & $\mathrm{CuO}, \mathrm{MgO}$ & $\mathrm{Cu}^{0}, \mathrm{Cu}_{2} \mathrm{O}, \mathrm{MgO}$ & 30 & 40 \\
2 & $10 \mathrm{CM}$ & 25 & $\mathrm{CuO}, \mathrm{MgO}$ & $\mathrm{Cu}^{0}, \mathrm{Cu}_{2} \mathrm{O}, \mathrm{MgO}$ & 45 & 60 \\
3 & $15 \mathrm{CM}$ & 18 & $\mathrm{CuO}, \mathrm{MgO}$ & $\mathrm{Cu}^{0}, \mathrm{Cu}_{2} \mathrm{O}, \mathrm{MgO}$ & 75 & 93 \\
4 & $20 \mathrm{CM}$ & 15 & $\mathrm{CuO}, \mathrm{MgO}$ & $\mathrm{Cu}^{0}, \mathrm{Cu}_{2} \mathrm{O}, \mathrm{MgO}$ & 108 & 145 \\
\hline
\end{tabular}

important role in determining the activity. No NB conversion was observed over CA catalyst as dehydration pathway is followed towards the formation of THF. Hence, the nature of the support will play a crucial role in governing the reaction pathway.

Later, using $\mathrm{MgO}$ as a suitable support, a catalyst series was made with $5,10,15$ and $20 \mathrm{wt} \%$ of $\mathrm{Cu}$ prepared by incipient wet impregnation method. The catalysts were denoted as 5CM, 10CM, 15CM and 20CM, respectively. Physical characteristics of these catalysts are displayed in table 3. Based on the surface area data, it is concluded that the blockage of $\mathrm{MgO}$ pores is by $\mathrm{CuO}$ or formation of solid solution.

Effect of metal loading on individual reactions (conversion of 1,4-butanediol to GBL and conversion of NB to ANL) for all the catalysts has been tested and it was found that the activity of catalysts is in the order:

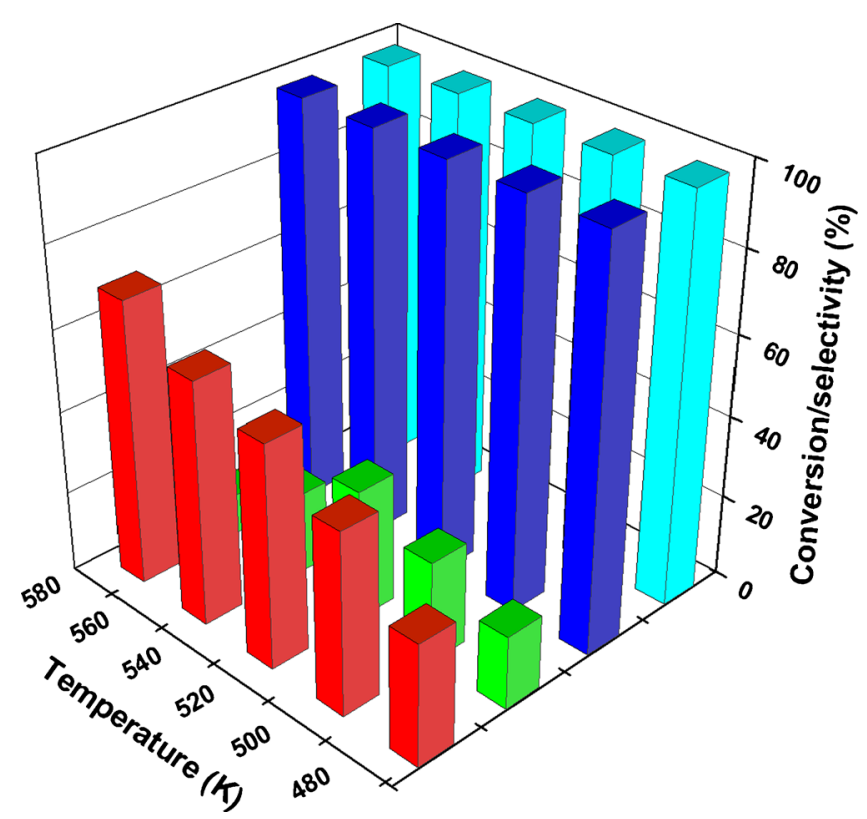

Figure 2. Effect of temperature on 20CM catalyst. Reaction conditions: $1 \mathrm{~atm}, 0.5 \mathrm{~g}$ catalyst, temperature range $=$ $473-573 \mathrm{~K}, 1,4 \mathrm{BDO} / \mathrm{NB}=3 / 2, \mathrm{~N}_{2}$ flow $=18 \mathrm{ml} / \mathrm{min}$. Conversion of 1,4 BDO. Conversion of NB. Selectivity to $1,4 \mathrm{GBL}$. Selectivity to ANL.
$20 \mathrm{CM}>15 \mathrm{CM}>10 \mathrm{CM}>5 \mathrm{CM}$. Although metal dispersion is higher at lower $\mathrm{Cu}$ loadings, 20CM exhibited higher activity because of the presence of higher $\mathrm{Cu}$ species that are active during coupling reaction. Therefore, effect of temperature on the coupling reaction has been conducted for 20CM catalysts. Figure 2 shows the effect of temperature on the activity of 20CM catalyst for the coupling reaction. It is found that $523 \mathrm{~K}$ is the optimum temperature for the coupling reaction, beyond this temperature, a decline in the conversion of NB is observed which may be due to competitive adsorption of both the reactants and due to the exothermic nature of NB hydrogenation. Liberated water vapour may be another factor responsible for decline in the conversion of NB during time on stream study. ${ }^{44,45}$

Recently, we have tried the coupling of 1,2butanediol and $\mathrm{NB}$ over $\mathrm{Cu} / \mathrm{SiO}_{2}$ catalyst $(20 \mathrm{wt} \%$ $\mathrm{Cu}$ loading) to synthesize 1-hydroxy 2-butanone (1, 2 $\mathrm{BDN}$ ) and aniline (ANL), respectively and the results are shown in figure 3. It is found that optimum temperature for the coupling reaction is $523 \mathrm{~K}$ and hence a

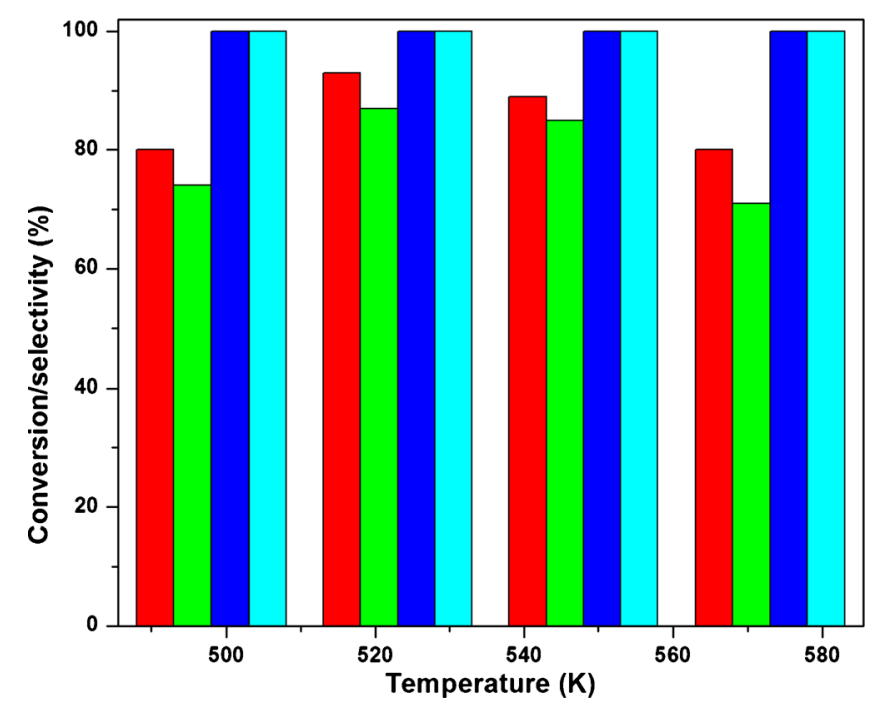

Figure 3. Effect of temperature over $\mathrm{Cu} / \mathrm{SiO}_{2}$ catalyst. Reaction conditions: 1 atm, $1 \mathrm{~g}$ catalyst, temperature range $=498-573 \mathrm{~K}, 1,2 \mathrm{BDO} / \mathrm{NB}=3 / 1, \mathrm{~N}_{2}$ flow $=20 \mathrm{ml} / \mathrm{min}$. Conversion of $1,2 \mathrm{BDO}$. Conversion of NB. Selectivity to $1,2 \mathrm{BDN}$. Selectivity to ANL. 


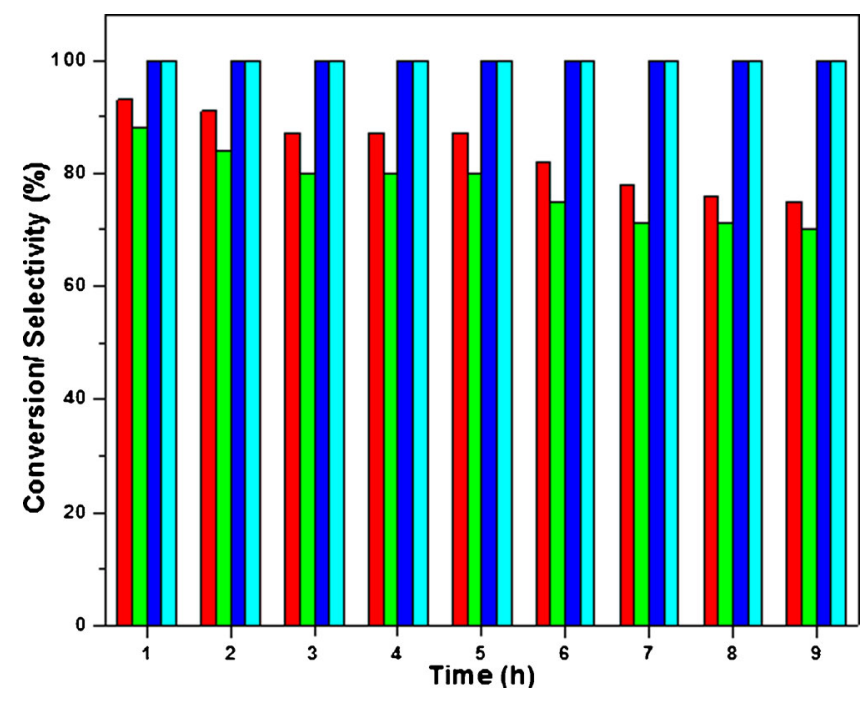

Figure 4. Time on stream studies over $\mathrm{Cu} / \mathrm{SiO}_{2}$ catalyst. Reaction conditions: 1 atm, $1 \mathrm{~g}$ catalyst, temperature $=$ $573 \mathrm{~K}, 1,2 \mathrm{BDO} / \mathrm{NB}=3 / 1, \mathrm{~N}_{2}$ flow $=20 \mathrm{ml} / \mathrm{min}$. Conversion of 1, 2 BDO. Conversion of NB. Selectivity to 1,2 BDN. Selectivity to ANL.

time on stream study has been conducted to evaluate the catalyst stability, depicted in figure 4. A gradual decrease in the activity of the catalyst is observed after $5 \mathrm{~h}$. The reason for deactivation is yet to be analysed.

Table 4 provides a brief history of coupled reactions using different catalyst systems. Keen observation reveals that most of these reactions used $\mathrm{Cu}$-based catalyst as it can dehydrogenate as well as hydrogenate the substrate. Moreover, these coupling processes proved that they are energetically favoured since the necessary heat required to drive the dehydrogenation reaction has been provided by the exothermic hydrogenation process when both of them are combined.

\section{Suggestions}

From the literature available so far on the coupled reactions, it is possible to formulate some of the suggestions.

(i) Reactions were performed so far on metal oxide supports, however, these reactions can be tried over mesoporous supports such as SBA-15, SBA16 , KIT-6, COK-12, etc. as they possess regular porous structure and high surface which may help in enhancement of activity.

(ii) New methods of catalyst preparation which increase metallic dispersion may be followed.

(iii) Reactions can be extended to asymmetric/chemoselective hydrogenations. These can be tried in the hydrogenation step so as to obtain a unique product.

(iv) Most coupling processes have never been tried at industrial scale; hence, a proper and sincere effort should be made to evaluate the aspects such as mass transfer limitations and thermodynamic limitations.

Table 4. Brief history of coupling reactions over different catalyst systems.

\begin{tabular}{lccc}
\hline Reaction & Catalyst system & Year & Reference \\
\hline Ethyl benzene $+\mathrm{CO}_{2}$ & $\mathrm{Sodium}$ oxide/ $\mathrm{Al}_{2} \mathrm{O}_{3}$ & 1988 & 8 \\
Ethyl benzene $+\mathrm{CO}_{2}$ & Activated carbon-supported iron catalyst & 1995 & 10 \\
Ethyl benzene $+\mathrm{CO}_{2}$ & Iron oxide catalysts & 1998 & 12 \\
Ethyl benzene + nitrobenzene & - & 2002 & 27 \\
Ethyl benzene + nitrobenzene & $\mathrm{Activated} \mathrm{carbon}$ & 2011 & 28 \\
1,4-Butanediol + maleic anhydride & $\mathrm{Cu}-\mathrm{Zn}-\mathrm{Al}$ & 2005 & 40 \\
1,4-Butanediol + maleic anhydride & $\mathrm{Cu}-\mathrm{Zn}$ & 2002 & 29 \\
n-butanol +maleic anhydride & $\mathrm{Cu}-\mathrm{Zn}-\mathrm{Ce}$ & 2008 & 43 \\
Ethanol + maleic anhydride & $\mathrm{Cu}-\mathrm{Al} \mathrm{O}_{3}, \mathrm{Cu}-\mathrm{ZnO}$ & 2009 & 46 \\
Ethanol + maleic anhydride & $\mathrm{Cu}-\mathrm{Zn}-\mathrm{Zr}$ & 2008 & 48 \\
n-Butanol + maleic anhydride & $\mathrm{Cu}-\mathrm{ZnO}-\mathrm{TiO} \mathrm{O}_{2}$ & 2006 & 41 \\
Cyclohexanol + furfural & $\mathrm{Cu}-\mathrm{Zn}-\mathrm{Al}$ & 2008 & 42 \\
Cyclohexanol + furfural & $\mathrm{Cu}-\mathrm{Mn}-\mathrm{Si}$ & 2007 & 32 \\
Cyclohexanol + furfural & $\mathrm{Cu}-\mathrm{MgO}-\mathrm{Cr} \mathrm{O}_{3}$ & 2011 & 31 \\
Cyclohexanol + furfural & $\mathrm{Cu}-\mathrm{MgO}$ & 2012 & 36 \\
Cyclohexanol + nitrobenzene & $\mathrm{Cu}-\mathrm{MgO}-\mathrm{Al}_{2} \mathrm{O}_{3}$ & 2013 & 37 \\
Cyclohexanol + nitrobenzene & $\mathrm{Cu}-\mathrm{MgO}-\mathrm{Al}_{2} \mathrm{O}_{3}$ & 1994 & 49 \\
2-Propanol + acetone & $\mathrm{Ru}-\mathrm{Pt}$ composite &
\end{tabular}




\section{Conclusion}

In this review, effort has been made to provide information regarding past and present status of coupled reactions. Earlier reports suggested that the presence of $\mathrm{CO}_{2}$ during $\mathrm{H}_{2}$ utilization enhanced the activity in dehydrogenation reaction in all the cases. Later, various industrially important products were synthesized simultaneously by changing the reactants. Studies that have been reported till now reveal the significance of the coupling of dehydrogenation and hydrogenation reactions, especially in terms of $\mathrm{H}_{2}$ economy and energy preservance, reduction in size and number of equipments. It is expected that molecular hydrogen is less reactive than the nascent hydrogen which is obtained in the dehydrogenation step. Also, preparation method of catalyst and selection of catalyst support plays a decisive role in its activity. Hence, every parameter pertaining to the support, active metal and preparation method has to be taken care of. The synergy between the two reactants has been wellexploited. Various suggestions were made in order to modify and increase the yield of the reaction. However, these coupled reactions need further research in order to be used in the industry. They can be considered as a useful source, keeping the world economy in view, to synthesize various products.

\section{Acknowledgements}

The authors CVP, CR and GVRB thank the Council of Scientific and Industrial Research (CSIR), University Grants Commission (UGC) and Department of Science and Technology (DST), New Delhi for the award of fellowships. All the authors thank the Council of Scientific and Industrial Research (CSIR), New Delhi for granting a project 'IndusMagic' under 12th Five year Network Programme.

\section{References}

1. American Chemical Society Report, Technology Vision 2020, the Chemical Industry, December 1996, http:// www/chemicalvision2020.com/ pdfs/chem vision.pdf

2. Ioana F, Ye W and Jacques C V 2012 Catal. Today 1892

3. Anastas P T and Warner J C 1998 Green chemistry, theory and practice (Oxford: Oxford University Press).

4. Leach Bruce E 1983 In Applied industrial catalysis, 1 (New York: Academic Press Inc.)

5. Jacobs G and Davis B H 2007 Low temperature water-gas shift catalysts (ed.) J J Spivey (London: Royal Society of Chemistry Publishing Catalysis) vol 20, p 122

6. Rahimpour M R, Dehnavi M R, Allahgholipour F, Iranshahi D and Jokar S M 2012 Appl. Energ. 99496
7. Towler G and Lynn S 1994 Chem. Eng. Sci. 492585

8. Sato S, Ohhara M, Sodesawa T and Nozaki F 1988 Appl. Catal A: Gen. 37207

9. Matsui J, Sodesawa T and Nozaki F 1991 Appl. Catal. A: Gen. 67179

10. Sugino M, Shimada H, Turuda T, Miura H, Ikenaga N and Suzuki T 1995 Appl. Catal. A: Gen. 121125

11. Badstube T, Papp H, Dziembaj R and Kustrowski P 2000 Appl. Catal. A: Gen. 204153

12. Mimura N, Takahara I, Saito M, Hattori T, Ohkuma K and Ando M 1998 Catal. Today 4561

13. Badstube T, Papp H, Kustrowski P and Dziembaj R 1998 Catal. Lett. 55169

14. Mimura N and Saito M 1999 Catal. Lett. 5859

15. Park J, Noh J, Chang J and Park S 2000 Catal. Lett. 65 75

16. Chen S, Qin Z, Sun A and Wang J 2009 Chinese J. Catal. 30359

17. Richuan R, Qingyun Z, Liu H, Yang H, Ling Q, Ming Y, Aimin Z and Wei C 2012 J. Mol. Catal. A: Chem. 363 283

18. David Raju B, Choi K M, Han S C, Abhishek B and Park S E 2007 Solid State Phenomena 1241737

19. David Raju B, Choi K M, Han S C, Abhishek B and Park S E 2007 Bull. Korean Chem. Soc. 2853

20. David Raju B, Choi K M, Han S C, Abhishek B and Park S E 2007 J. Mol. Catal. 26958

21. David Raju B, Choi K M, Lee J H, Han D S and Park S E 2007 Catal. Commun. 843

22. David Raju B, Choi K M, Han D S, Koo J B and Park S E 2006 Catal. Today 115242

23. Elnashaie S S E H, Moustafa T, Alsoudani T and Elshishini S S 2000 Chem. Eng. Sci. 241293

24. Moustafa T M and Elnashaie S S E H 2000 J. Membr. Sci. 178171

25. Aling S, Zhangfeng Q and Jianguo W 2002 Catal. Lett. 791

26. Abashar M E E 2004 Chem. Eng. Process. 431195

27. Nabeel S, Abo-Ghander F, Grace J R, Jan F M V, Said S E H E and Jim Lim C 2010 Chem. Eng. Sci. 653113

28. Anna M and Mieczysław K 2011 Chem. Eng. J. 171 1348

29. Zhu Y L, Xiang H W, Wu G S, Liang B and Li Y W 2002 Chem. Commun. 254

30. Jun Y, Zheng H Y, Zhu Y L, Zhao G W, Zhang C H, Teng B T, Xiang H W and Li Y W 2004 Catal. Commun. 5505

31. Nagaraja B M, Padmasri A H, David Raju B and Rama Rao K S 2011 Int. J. Hyd. Energy 363417

32. Nagaraja B M, Padmasri A H, Seetharamulu P, Hari Prasad Reddy K, David Raju B and Rama Rao K S 2007 J. Mol. Catal. A: Chem. 27829

33. Rama Rao K S, David Raju B, Narayanan S, Nagaraja B M, Padmasri A H, Siva Kumar V, Shashikala V, Seetharamulu P and Sreevardhan Reddy S 2006 US 7015359

34. Hari Prasad Reddy K, Rahul R, Sree Vardhan Reddy S, David Raju B and Rama Rao K S 2009 Catal. Commun. 10879

35. Hari Prasad Reddy K, Anand N, Venkateswarlu V, Rama Rao K S and David Raju B 2012 J. Mol. Catal. A: Chem. 355180 
36. Pramod C V, Suresh M, Mohan V, Sridevi B, David Raju B and Rama Rao K S 2012 Curr. Catal. 1140

37. Pramod C V, Mohan V, David Raju B and Rama Rao K S 2013 Catal. Lett. 143432

38. Seetharamulu P, Siva Kumar V, Padmasri A H, David Raju B, Rama Rao K S 2007, J. Mol. Catal. A: Chem. 263253

39. Hari Prasad Reddy K, Anand N, Sai Prasad P S, Rama Rao K S and David Raju B 2011 Catal. Commun. 12 866

40. Zhu Y L, Jun Y, Dong G Q, Zheng H Y, Xiang H W and Li Y W 2005 Appl. Catal. B: Environ. 57183

41. Zheng H Y, Zhu Y L, Bai Z Q, Long H, Xiang H W and Li H W 2006 Green Chem. 8107

42. Zheng H Y, Zhu Y L, Long H, Zeng Z Y, Wan H Z and Li H W 2008 Catal. Commun. 9342
43. Zhang D, Yin H, Zhang R, Xue J and Jiang T 2008 Catal. Lett. 122176

44. Sangeetha P, Seetharamulu P, Shanthi K, Narayanan S and Rama Rao K S 2007 J. Mol. Catal. A: Chem. 273 244

45. Mohan V, Pramod C V, Suresh M, Hari Prasad Reddy K, David Raju B and Rama Rao K S 2012 Catal. Commun. 1889

46. Dezhi G, Yonghai F, Hengbo Y, Aili W and Tingshun J 2013 Chem. Eng. J. 233349

47. Zhang D, Yin H, Ge C, Xue J, Jiang T, Yu L and Shen Y 2009 J. Ind. Eng. Chem. 15537

48. Zhang R, Yin H, Zhang D, Qi L, Lu H, Shen Y and Jiang T 2008 Chem. Eng. J. 140488

49. Saito Y, Yamashita M, Ito E and Meng N 1994 Int. J. Hyd. Energy 19223 